\title{
Training Scholars to Study Non-Scholarly Life
}

\author{
Benjamin Geer, University of Basel
}

\begin{abstract}
Working paper
The published version is a chapter in Teaching Islamic Studies in the Age of ISIS, Islamophobia, and the Internet, edited by Courtney M. Dorroll. Bloomington, Indiana: Indiana University Press (2019).
\end{abstract}

In the scholastic fallacy, the researcher explains the actions of people in nonscholarly situations by projecting scholarly thinking onto them. After introducing the concept and discussing a recent example from Islamic studies, I suggest that certain social structures may make this error more likely. Focusing on the case of research in Egypt, I argue that degree programs are not designed to enable students to learn Arabic as a second language well enough to do research that involves talking with people there. Egyptian state institutions also restrict both ethnographic and archival research. These obstacles are likely to deter research on ordinary social practices, on vernacular cultural production, and on archival materials, and to favor research on canonical texts. Moreover, in a field such as Islamic studies, in which researchers can produce work that responds to the demands of non-specialist audiences, students may be tempted to overgeneralize from these texts, e.g. by relying on them to draw conclusions about Islam in general. I suggest ways for universities and faculty to help students avoid these pitfalls.

\section{The Scholastic Fallacy}

Hughes (2014) criticizes certain scholars in the field of Islamic studies for constructing apologetic accounts of Islam at the expense of sound scholarship. He attributes this to theological stances, as well as to the understandable desire to counter widespread Islamophobia by describing an allegedly authentic liberal Islam $(2-3,34,66)$. This may be true, but one can also interpret this impulse as an 
example of a more general phenomenon, by seeing it as an effect of the relationship between the field of Islamic studies and actors outside the field. Unlike a field such as mathematics, where results are mainly of interest to specialists, Islamic studies can produce ideas that respond to the demands of non-specialists, many of whom are interested in conclusions about Islam in general, whether these conclusions are positive or negative.

There is nothing wrong with trying to make valid generalizations about Islam, as long as they are based on adequate evidence. In contexts where it is difficult or impossible to do research involving direct communication with and observation of people in everyday life, it may be tempting to use texts as a substitute. This is a form of what sociologist Pierre Bourdieu (1997, 49-84) called the scholastic fallacy. For example, to see a work of Islamic philosophy as reflecting the beliefs and practices of Muslims in general, one must ignore the specificity of the social conditions in which philosophical texts are produced, as well as the difference between the theoretical thinking involved in philosophy and the practical thinking employed (even by philosophers) in everyday life.

To produce a work of philosophy, an individual must have a certain "distance from economic and social necessity" (15). This usually requires a privileged social position, which provides enough leisure time to make it possible to engage in philosophical study and writing. This leisure is a necessary, but not sufficient, social condition of the "scholastic disposition which inclines its possessors to suspend the demands of the situation, the constraints of economic and social necessity, and the urgencies it imposes or the ends it proposes." This disposition is what "incites people ... to raise problems for the pleasure of solving them, and not because they arise in the world, under the pressure of urgency, or to treat language not as an instrument but as an object of contemplation, formal invention or analysis" (12-13).

Moreover, to be accepted and recognized as a philosopher, an individual must have internalized certain dispositions and conceptual schemas as a participant in a field of knowledge production, in which she is in competition with peers for recognition (10-11). Each text reflects the shared assumptions of the participants in the field at a given historical moment, which made it possible for them to ask certain questions and not others (96-97). A text is also the response of an individual occupying a certain position in the field (e.g. a dominant or dominated position, or a position in a subfield), to the state of play in the field at that moment (Bourdieu 1996, 87-88).

In contrast, "practical sense," which everyone, including off-duty philosophers, relies on in everyday life, is adapted to action rather than contemplation (Bourdieu 1990, 103-4):

This practical sense, which does not burden itself with rules or prin- 
ciples (except in cases of misfiring or failure), still less with calculations or deductions, which are in any case excluded by the urgency of action ... is what makes it possible to appreciate the meaning of the situation instantly, at a glance, in the heat of the action, and to produce at once the opportune response.

Bourdieu argues that, instead of rules or principles, practical sense mobilizes dispositions that "result from a durable modification of the body through its upbringing" (Bourdieu 1997, 139). In short, in the social worlds of everyday life, we "learn bodily" (141):

The most serious social injunctions are addressed not to the intellect but to the body, treated as a "memory pad." The essential part of the learning of masculinity and femininity tends to inscribe the difference between the sexes in bodies ... in the form of ways of walking, talking, standing, looking, sitting, etc.... As much in everyday pedagogic action ("sit up straight," "hold your knife in your right hand") as in rites of institution, this psychosomatic action is often exerted through emotion and suffering, psychological or even physical....

When researchers imagine that all thinking is like scholastic thinking, they tend to make the mistake of trying to explain people's actions in non-scholastic situations in terms of scholastic ideas (51):

Projecting his theoretical thinking into the heads of acting agents, the researcher presents the world as he thinks it (that is, as an object of contemplation, a representation, a spectacle) as if it were the world as it presents itself to those who do not have the leisure (or the desire) to withdraw from it in order to think it. He sets at the origin of their practices, that is to say, in their 'consciousnesses', his own spontaneous or elaborated representations, or, worse, the models he has had to construct ... to account for their practices.

Critiques of certain ways of studying and teaching Islam have drawn attention to some of the manifestations of the scholastic fallacy. Edward Said's Orientalism pointed out the folly of assuming "that the swarming, unpredictable, and problematic mess in which human beings live can be understood on the basis of what books-texts-say," and criticized a type of pedagogy based on "a canon of textual objects passed on from one generation of students to the next" (Said 1979, 93, 129). Among anthropologists interested in Islam, there has been a lively debate about whether religious practices can be understood merely as symbols to be interpreted (see Bush 2012); for Bourdieu, the attempt to read practices as if 
they were texts is another manifestation of the scholastic fallacy (Bourdieu 1997, 52). However, the basic misconception underlying these manifestations, i.e. the confusion between scholarly thinking and practical sense, does not seem to have been a focus of discussion in Islamic studies or in scholarship about teaching Islam.

Recent assessments of the state of Islamic studies observe that the field has made progress in moving beyond the confines of textual sources, by increasingly accommodating social science methods such as ethnography (Kurzman and Ernst, 2012, 31; Aishima, 2012, 170; Bennett, 2013, 261). Still, Ernst and Martin $(2010,13)$ note that "job descriptions in vacancy announcements still tend to focus narrowly on expertise in classical languages and texts. That is, very frequently a job in Islamic studies is defined exclusively as the study of classical Arabic texts such as the Qur'an and the foundational texts of Islamic law." This no doubt encourages the scholastic inclination to see practices simply as reflections of texts.

One recent example is the much-discussed book What Is Islam? (Ahmed 2016). Its merits include the author's insistence on constructing a descriptive rather than prescriptive account of Islam, and his rejection of preconstructed categories such as 'religion' and 'culture.' However, like most the scholarship it critiques, it presents scholastic views of Islam as representative of Islam in general. This is particularly apparent in Ahmed's discussion of Sufism, which he correctly describes as "a foundational, commonplace and institutionalized conceptual and social phenomenon in societies of Muslims" over a long historical period (20). While this at first seems as if it might lead him to an exploration of the structures of the social practices involved in Sufism, Ahmed seems to view Sufism merely as the expression of the "higher Sufi thought" of Sufi philosophers and poets such as Muhyi al-Din 'Ibn Arabi and Jalal al-Din Rumi (20-22).

Ahmed anticipates the objection that this textual evidence is merely "representative of elite society and culture, and that the society of elites is necessarily unrepresentative of society-at-large." In fact, he argues, the ideas of these elites were disseminated from elite textual sources to a wide audience via "vernacular primers, as well as, and most importantly, the translation, configuration and dramatization of these ideas into poetical and narrative fiction," such as poetry "sung to popular (and, often, illiterate) audiences at Sufi shrines throughout the Indus valley" (85-88). In his view, such texts are a "means of circulation and mobilization of the ideas, values and norms of high intellectual culture for instruction, contemplation, and criticism in society-at-large" (92):

[T] he vast majority of the population of pre-modern societies of Muslims participated in the normative truth-claims and vocabulary of the hierarchical cosmologies of Sufism.... [I]ndeed, an ordinary Mus- 
lim's ziyarah to obtain the barakah that emanates from the tomb of a Sufi in a village or mountain pass in Morocco, India or Indonesia is precisely a de facto acknowledgement of an active participation in a cosmos organized and structured and experienced in Neo-Platonic, Avicennan, and Akbarian terms.

This account of Sufism can be contested with ethnographic evidence, particularly since Ahmed has switched from the past tense ("participated") to the present ("is"). For example, in Turkey, Silverstein (2007, 42) attended many sohbets, which were meetings of a shaykh and his disciples, "structured around the reading and discussion" of hadith:

Yet there was nothing ostensibly "mystical" about the content of the discussions that took place, occupying roughly 95 per cent of the time of the sohbet. I had attended sohbets and socialized with cemaat members for several months when I realized that almost no one had ever discussed the classic themes of Sufism emphasized in Western literature on the topic, such as "intimate experience of God" and "self-effacement (in the Reality of God)." Not only were these techniques not discussed during sohbet, they were not discussed among the many followers outside of sohbets. It became quite obvious that the members of the cemaat simply were not particularly concerned with these themes on a daily basis.

Similarly, Hoffman (1995) found that philosophy seemed to play little or no role in the lives of the participants in the Sufi orders she studied in Egypt; they were instead focused on obedience to a shaykh, the physical practice of chanting and movement in the dhikr, and devotion to the prophet Muhammad and his family. The most widely read Sufi books were "largely collections of brief biographies of Sufi saints," and some shaykhs disdained reading as a way of learning about Sufism, or were illiterate $(22-23,137)$. Most Sufi songs were songs of praise to the prophet Muhammad (64). While Hoffman (1995, 175-76) does describe a munshid who sang "of the mysteries of divine knowledge and longing to enter the presence of God," her skepticism about the audience's reception of these performances is apt:

One is astonished at the density of such songs sung before a largely uneducated audience, sung indeed by a man who lacks much formal education himself. We may well be convinced of the truth that each one will understand only according to his capacity and of the utter impossibility of the average person to appreciate the full import of the words while at the same time doing dhikr. 
Even if Ahmed's claim that ordinary Sufis absorb philosophical ideas from vernacular texts were true, his description of Sufism would still miss everything in it that is based on practical sense, rather than on scholastic discourses. When Hoffman (1995, 167) asked a shaykh "whether the movements of dhikr help a person come to God," the shaykh replied:

They don't help him get to God, but they help him to train his limbs to do dhikr. Because there is a dhikr of the body and its parts. There is a dhikr of the limbs, of the eye, of the hand. Dhikr must be perfected in the disciple. When all his faculties are doing dhikr, then he recollects nothing but God. All his bodily parts are directed toward one goaldhikr.

Whether or not this type of physical training imparts any understanding of Sufi philosophy, it establishes the shaykh as a model to be imitated, a model of a particular practical sense that his followers can internalize through physical participation: the shaykh moves and chants in a certain way, and "[a]ll the participants in the dhikr imitate these utterances and bodily movements" (Pinto 2009, 130). Thus Sufi practice is, in a way, like "some universes, such as those of sport, music or dance," which "demand a practical engagement of the body," and in which trainers "seek effective ways of speaking to the body" rather than to the intellect (Bourdieu 1997, 144). But it is much more than this, because the shaykh is viewed as a model of Islamic practice, having special knowledge of God. In return for imitation of his practical sense, the shaykh can reward his followers with what Bourdieu describes as "the grace (charisma) which saves those it touches from the distress of an existence without justification and which gives them ... a theodicy of their existence" (241).

It is reasonable to ask whether the shaykh's power over his followers depends at least partly on the fact that the conceptual schemas that they rely on in their perception of him and of themselves have been shaped by the training they have received from him and by their efforts to imitate him (and, if their parents were also Sufis, by the upbringing they received at home). If so, we can interpret this power as an example of what Bourdieu calls "symbolic power" (171):

Symbolic power is exerted only with the collaboration of those who undergo it because they help to construct it as such.... This submission is in no way a "voluntary servitude" and this complicity is not granted by a conscious, deliberate act; it is itself the effect of a power, which is durably inscribed in the bodies of the dominated, in the form of schemes of perception and dispositions (to respect, admire, love, etc.).... 
These dispositions manifest themselves in spontaneous physical reactions: the shaykh's followers feel "a mixture of respect and fear" in his presence, and lower their eyes; one said, "When I found myself in the presence of the shaykh ... I was overcome by a feeling of fear, as if I had unwittingly done something wrong" (Chih 2007, 31). Such reactions are typical reflections of the relation of symbolic power (Bourdieu 1997, 169):

The practical recognition through which the dominated, often unwittingly, contribute to their own domination by tacitly accepting, in advance, the limits imposed on them, often takes the form of bodily emotion (shame, timidity, anxiety, guilt).... It is betrayed in visible manifestations, such as blushing, inarticulacy, clumsiness, trembling, all ways of submitting, however reluctantly, to the dominant judgement....

In turn, shaykhs display their power in a variety of ways: they "regularly test their disciples by ignoring them, keep them waiting, assigning humiliating tasks to them, and treating them rudely" (Hoffman 1995, 144). The physical act of making someone wait, for example, is one of the most common ways of manifesting power (Bourdieu 1997, 228). Most importantly, the social relation of domination between the shaykh and his followers serves practical purposes (Chih 2007, 32-33):

But it is especially to seek his help in arbitration that people come to see the shaykh.... The shaykh is also a political notable, even though he would not describe himself as such. He holds local power as a result of his political connections with the government, due to which he can intervene effectively on behalf of the community. $\mathrm{He}$ is a member of the ruling party.... Government officials often have recourse to him for taking care of problems in the village.... Once the followers have recognized the presence of walaya in the shaykh, they establish a relationship of allegiance with him that sociologically takes the form of a patron-client relationship.... The relations of patronage that we have noted in the Egyptian case, where the shaykh takes care of the needs of the community, are inherent in the very concept of walaya: proximity to God implies patronage.... The people of the village experience their relationship with the shaykh as one of exchange and mutual benefits, which they exploit themselves.

Thus it is not surprising that Chih $(2007,28)$ found that the relationship between the shaykh and his followers overshadows everything else in their experience of Sufism: 
When one asks Sufis what distinguishes them from those who are not Sufis, one receives answers such as "love of the shaykh" ( $m a-$ habba li-l-shaykh), "attachment to the shaykh" (mulazamat al-shaykh), or "putting oneself at the shaykh's service" (khidmat al-shaykh).

These practices of domination and patronage are part of Sufism, just as much as the philosophy of Ibn 'Arabi is part of Sufism. One can have some chance of understanding these practices only by observing them in everyday life, rather than by reading theoretical or normative texts. This is not a matter of making a distinction between "elite Islam" and "popular Islam." Scholars, too, rely on practical sense in everyday life whenever they are not actually doing scholarship. Instead, the scholar must distinguish between two ways of understanding the world: "the scholastic one which he tacitly sets up as the norm, and the practical one which he has in common with men and women seemingly very distant from him in time and social space," and which he, too, uses "in the most ordinary acts and experiences (those of jealousy, for example) of ordinary existence" (Bourdieu 1997, 51).

\section{The Neglect of Training in Spoken Arabic}

A researcher wishing to observe and listen to people in everyday life in Arabicspeaking countries must be proficient in spoken Arabic. But outside the Arab world, most universities that offer courses in Arabic as a second language teach only standard Arabic, a variety that is reserved for written communication and a small number of very formal or official contexts. Although surveys indicate that conversing with native speakers is a high priority for students, instruction in spoken varieties of Arabic is rare. Most degree programs offer a maximum of two semesters of spoken Arabic. Students who study only standard Arabic "often experience frustration and embarrassment when trying to communicate with Arabic speakers," and are, in effect, excluded from everyday social practices (Palmer 2007, 111-12; Wilmsen 2013, 133).

The main opportunity for students to learn spoken Arabic as a second language is in study-abroad programs. However, these programs are also, at most, two semesters long (Jensen and Howard 2014, 32), and "study abroad sojourns are becoming ever shorter-a semester, summer, or even just a few weeks, rather than an entire academic year" (Trentman 2013, 457). Studies have found that a longer period of immersion is correlated with greater gains in oral proficiency (Vande Berg, Connor-Linton, and Paige 2009; Davidson 2010), but degree programs do not give students the opportunity to take advantage of this.

After only one year of immersion, most students will struggle to do research that involves talking with people, or studying vernacular media such as film and 
television, especially if they have had little previous training in spoken Arabic. In my own experience, the non-native speakers who have reached an advanced level in Egyptian colloquial Arabic, enabling them to use it extensively and with ease in their research, have devoted a minimum of two years in Egypt to language training and immersion. Some have managed to do this by, in effect, creating their own study-abroad program, using their own financial resources, but this is not feasible for most students. Others have progressed to an advanced level in spoken Arabic while at the same time doing field research for a graduate degree, but this is clearly not ideal.

Faced with such limited opportunities to learn spoken Arabic, students have an incentive to choose research topics that involve only written sources. They may therefore refrain from asking research questions that can be answered only through ethnography, interviews, or the study of vernacular media. Or they may try to answer those questions using written sources alone, and thus fall into the scholastic fallacy.

Since Egyptian anthropologists produce high-quality research using their native language, one might well ask whether, given scarce resources, it would be more efficient if only native speakers did this type of research. However, as Sholkamy (1999, 134) observes, favoring local researchers over foreign ones "promotes a kind of nationalism that cannot further understanding per se." In another undesirable scenario, foreign researchers, who do not speak the local language, treat local researchers as mere "service providers' for research assistants, for translating, and newspaper summaries, for first hand testimonies, and time and again as providers of experts" (Abaza 2011). Instead, "anthropologists at home and abroad need to stay on shared intellectual territory. Ideally we should all work at home and work abroad and thus have a greater sensitivity to one another" (Sholkamy 1999, 134).

\section{The Risks of Research in Authoritarian States}

Field research in authoritarian states involves particular methodological and ethical problems. In a survey of researchers who did fieldwork in authoritarian states in northern Africa and western Asia, many respondents described "a pervasive 'culture of suspicion,' as evidenced by interviewees' mistrust and nervousness in speaking frankly to researchers for fear of political repercussions," and reported "the common perception that American researchers in general may be connected with the CIA or other intelligence agencies" (Clark 2006, 418; see also Radsch 2009, 98). Carapico (2006, 430) notes that laypeople without university degrees are likely to have the impression that research is something akin to spying. Moreover, it can put both the researcher and the participants at risk: 
More pernicious than neighborhood gossip, however, is the fact that security agents, secret police, and ordinary snitches may indeed track a foreigner's moves and conversations.... In many Arab countries it is common knowledge that telephones are tapped, for instance, and dialing a number, perhaps especially from abroad, may bring that phone line under surveillance. Mail is opened and read by censors. The principled quandary under these circumstances is whether one's colleagues will become targets of police scrutiny-or worse.

In the context of survey-based research, the problem of respondent self-censorship (known as "preference falsification") is well-known, but "survey-based research on public opinion in authoritarian regimes ... has mostly tried to avoid a direct discussion of this issue" (Jiang and Yang 2016, 601-602). Clark (2006, 418) found that this made some researchers wonder whether "the fear of answering survey questions honestly may have invalidated the survey results," but it is not clear how this problem can be solved.

Sholkamy (1999, 127-29) describes how both bureaucratic and security obstacles discourage ethnographic research in Egypt. Social scientists cannot legally carry out research in Egypt without a permit from the Center for Public Mobilization and Statistics (CAPMAS), which can reject applications without explanation. Moreover, CAPMAS recognizes only survey research, not ethnographic research, and requires the researcher to submit the written questionnaire that will be used in the survey. Some anthropologists have found no alternative to inventing a fake questionnaire in the hope of obtaining a permit.

Before the uprising of 2011, it was common for researchers to carry out interview-based or ethnographic studies in Egypt without permits, perhaps with a letter from their home institution, taking the chance that the authorities would not notice or care. The risks of this approach seem to have increased since then. In a context of increased xenophobia, in which the media have regularly portrayed foreigners as spies or agents seeking to destabilize Egypt, several foreign researchers have been arrested, deported and/or banned from entering the country, with no official explanation (Rohan and Mazen 2016). In January 2016, Giulio Regeni, a Cambridge University PhD student who had been doing fieldwork on trade unions in Egypt, disappeared in Cairo; his body was found by a roadside nine days later, bearing extensive signs of torture. As of this writing, Egyptian human rights groups and Italian investigators suspect that Egyptian security services may be responsible, but the case remains unsolved (Stille 2016). At the very least, it suggests that the risks of doing research that involves talking to people in Egypt have increased considerably in recent years.

In some cases, a researcher might be tempted to carry out interviews from abroad using video calls transmitted over the Internet. While this reduces the 
risk for the researcher, it is much more difficult to protect the interviewee. Authoritarian states have sophisticated surveillance technology, and even if the call is encrypted to prevent interception in transit, an intelligence agency may find other ways to monitor it (Deibert 2015, 65-69).

Research in archives is perhaps safer but can be no less daunting. In the wake of the revolutionary uprisings that took place in several countries in northern Africa and western Asia starting in 2010, archival research has become more difficult in some countries and impossible in others, and historians now "face the prospect of ever-diminishing access to archives and national libraries in the region" (El Shakry 2015, 922). In the case of Egypt, the obstacles to archival research are considerable (Omar 2015, 176):

Unlike other world-class document repositories ... the National Archives of Egypt are not open to the public. Access is limited to those with permits, and it is the state's repressive security apparatus that acts as arbiter... [S]tate security viciously restricts access to all but a privileged few; these people tend to be professional historians whose research is perceived as nonsubversive to the state and its narratives, which are overwhelmingly nationalist.

Many official documents remain unavailable, their whereabouts unknown. In particular, there is almost no access to official documents dating from after the 1952 military coup; historians have therefore had to rely "almost entirely on foreign archives, the press, interviews and personal memoirs" (Gorman 2003, 74).

The periodicals section of the Egyptian National Library has offered unrestricted access, but it has no digitized materials (only bound volumes and microfilm, many of which are missing), there is no electronic catalog and no index of any kind, and the process of obtaining each item is very slow. Therefore, a researcher must either know in advance exactly which materials he wants, or have a great deal of time to spend reading volume after volume in the hope of finding something of interest. In practice, this means that there are many research questions that cannot be asked or are unlikely to be asked.

The state of audiovisual archives in Egypt is even worse. Egypt has had the most prolific Arabic film industry since the early 20th century, and Egyptian films have long been popular throughout the Arabic-speaking world (Shafik 2007, 4-5). Egyptian cinema is thus an important record of interaction between cultural producers and a wide audience over a long period of time. However, preservation at Egypt's National Film Center is utterly inadequate, and hundreds of films have been lost because of neglect (Badreya 2002, 417-19; Weissberg 2010). Many films that have been preserved cannot be viewed, unless their distribution via television or DVD is still considered commercially viable. 
Given these obstacles, it is not surprising that " $[\mathrm{r}]$ esearch agendas, instead of being problem-driven, are often guided by what material is available or even accessible" (Omar 2015, 177). This is a problem in itself, because the narrowing of available materials impoverishes research by narrowing the range of questions that can be asked. A less obvious risk is the temptation to overgeneralize from limited sources, to make them say things that they cannot really say. I have discussed above how this can happen with canonical texts, but it also affects the increasingly common attempts to use social media as a substitute for surveys based on probability sampling. Social media users are not representative of the broader population, fake accounts are often created to spread propaganda (GayoAvello 2013), and automated sentiment analysis is poorly equipped to recognize sarcasm and irony (Bamman and Smith 2015).

\section{Conclusion}

Degree programs that involve training in Arabic should give spoken Arabic at least as high a priority as standard Arabic, e.g. by integrating them in the same course of instruction, using spoken Arabic for oral communication in the classroom, and standard Arabic for reading and writing (see Younes 2015). At more advanced levels, it would seem reasonable to emphasize content-based instruction (otherwise known as content and language integrated learning). It is common for French departments outside the Francophone world to teach courses in literature, history, and philosophy in French, but only a few universities outside the Arab world offer any content courses in Arabic, and this approach should be more widely used.

Study-abroad programs of at least two years should be offered as part of degree programs. The structure of such programs is as important as their duration, because mere presence in a country is not enough to guarantee language immersion. One way to improve language immersion while at the same time promoting ethnographic research is to integrate ethnography into the study-abroad program (Trentman 2013, 469):

In these types of programs, students receive substantial pre-departure training in conducting ethnographic research.... While abroad, they conduct a small ethnography connected to their local environment. This connects their more general knowledge to the local context they encounter, promotes interactions with locals via data collection, helps them overcome ethnocentric orientations, and assists linguistic development through the need to collect and analyze information in the target language beyond superficial interactions. 
Research in an authoritarian state should always be designed so that it can be adapted if the situation there makes the fieldwork impossible or too risky. One way to do this is to design a project involving two or more countries (e.g. a comparative study), thus making it less dependent on the situation in any particular country.

A number of universities and national libraries around the world have collections of rare books, periodicals, and other materials that, to some extent, overlap with the contents of hard-to-access libraries and archives in authoritarian states. By digitizing these materials and making them freely accessible on the Internet, these institutions can help shield research from the interference of internal security services in those states. Better still, by providing full-text and other search capabilities, they can make it possible to carry out research that would not otherwise be feasible. It is especially valuable to create open-access digital archives of non-canonical texts, such as correspondence, commercial and legal documents, newspapers, popular magazines, and school textbooks, which can provide glimpses of everyday social practices.

Finally, when students carry out research on canonical texts, they should be encouraged to historicize those texts, understanding each one as a stance taken in relation to the state of a particular field at a particular historical moment, by an author occupying a particular position in that field, rather than as a timeless expression of broader social phenomena. This approach requires humility based on the recognition that, with only texts as evidence, one can try to answer some questions but not others.

\section{References}

Abaza, Mona. 2011. "Academic Tourists Sight-seeing the Arab Spring." Ahram Online (September 26). http : / / english . ahram .org . eg/News / 22373. aspx.

Ahmed, Shahab. 2016. What Is Islam? The Importance of Being Islamic. Princeton and Oxford: Princeton University Press.

Aishima, Hatsuki. 2012. "Contesting Public Images of 'Abd al-Halim Mahmud (1910-78): Who is an Authentic Scholar?” In Ethnographies of Islam: Ritual Performances and Everyday Practices, edited by Baudouin Dupret, Thomas Pierret, Paulo G. Pinto, and Kathryn Spellman-Poots, 170-78. Edinburgh: Edinburgh University Press. IsBN: 9780748689842.

Badreya, Sayed. 2002. "Saving Egyptian Film Classics." In This Film Is Dangerous: A Celebration of Nitrate Film, edited by Roger Smither and Catherine A. Surowiec, 417-420. Brussels: International Federation of Film Archives. 
Bamman, David, and Noah A. Smith. 2015. "Contextualized Sarcasm Detection on Twitter." In International AAAI Conference on Web and Social Media. http: //www . aaai .org/ocs/index.php/ICWSM/ICWSM15/paper/view/10538.

Bennett, Clinton. 2013. "New Directions: The Who, Why, What, How, and Where of Studying Islam." In The Bloomsbury Companion to Islamic Studies, edited by Clinton Bennett, 259-82. New York: Bloomsbury. ISBN: 9781441127884.

Bourdieu, Pierre. 1990. The Logic of Practice. Translated by Richard Nice. Stanford: Stanford University Press.

- 1996. The Rules of Art. Translated by Susan Emanuel. Cambridge: Polity Press.

1997. Pascalian Meditations. Translated by Richard Nice. Stanford: Stanford University Press.

Bruinessen, Martin van, and Julia Day Howell, eds. 2007. Sufism and the Modern in Islam. London: I.B. Tauris.

Bush, Stephen S. 2012. "Are Meanings the Name of the Game? Religion as Symbolic Meaning and Religion as Power." Religion Compass 6 (12): 525-533. IssN: 1749-8171. doi: $10.1111 / \mathrm{j}$.1749-8171.2012.00361.x.

Carapico, Sheila. 2006. "No Easy Answers: The Ethics of Field Research in the Arab World." PS: Political Science and Politics 39 (3): 429-431. http : //www . jstor.org/stable/20451778.

Chih, Rachida. 2007. "What is a Sufi Order?" In Bruinessen and Howell 2007, 2138.

Clark, Janine A. 2006. "Field Research Methods in the Middle East." PS: Political Science and Politics 39 (3): 417-423. http : / / www . jstor . org/stable / 20451776.

Davidson, Dan E. 2010. "Study Abroad: When, How Long, and With What Results? New Data from the Russian Front." Foreign Language Annals 43 (1): 6-26. ISSN: 1944-9720. doi:10.1111/j.1944-9720.2010.01057.x.

Deibert, Ron. 2015. “Cyberspace Under Siege." Journal of Democracy 26 (3): 6478. doi:10.1353/jod.2015.0051.

El Shakry, Omnia. 2015. “'History without Documents': The Vexed Archives of Decolonization in the Middle East." The American Historical Review 120 (3): 920-934. doi:10.1093/ahr/120.3.920. 
Ernst, Carl W., and Richard C. Martin. 2010. "Introduction: Toward a Post-Orientalist Approach to Islamic Religious Studies." In Rethinking Islamic Studies: From Orientalism to Cosmpolitanism, edited by Carl W. Ernst and Richard C. Martin, 1-22. Columbia: University of South Carolina Press. ISBN: 9781570038938.

Gayo-Avello, Daniel. 2013. "A Meta-Analysis of State-of-the-Art Electoral Prediction From Twitter Data." Social Science Computer Review 31 (6): 649-679. doi:10.1177/0894439313493979.

Gorman, Anthony. 2003. Historians, State and Politics in Twentieth Century Egypt: Contesting the Nation. New York and Abingdon: RoutledgeCurzon.

Hoffman, Valerie. 1995. Sufism, Mystics, and Saints in Modern Egypt. Columbia: University of South Carolina Press.

Hughes, Aaron W. 2014. Theorizing Islam: Disciplinary Deconstruction and Reconstruction. New York and Abingdon: Routledge. ISBN: 9781844657902.

Jensen, Julia, and Martin Howard. 2014. "The Effects of Time in the Development of Complexity and Accuracy During Study Abroad: A Study of French and Chinese Learners of English.” EUROSLA Yearbook 14 (1): 31-64. ISSN: 15681491. doi:10.1075/eurosla.14.02jen.

Jiang, Junyan, and Dali L. Yang. 2016. "Lying or Believing? Measuring Preference Falsification From a Political Purge in China." Comparative Political Studies 49 (5): 600-634. doi:10.1177/0010414015626450.

Kurzman, Charles, and Carl W. Ernst. 2012. "Islamic Studies in U.S. Universities." Review of Middle East Studies 46 (1): 24-46. doi:10. 1017/S2151348100002974.

Omar, Hussein. 2015. "The State of the Archive: Manipulating Memory in Modern Egypt and the Writing of Egyptological Histories." In Histories of Egyptology: Interdisciplinary Measures, edited by William Carruthers, 174-184. New York and Abingdon: Routledge.

Palmer, Jeremy. 2007. "Arabic Diglossia: Teaching Only the Standard Variety Is a Disservice to Students." Arizona Working Papers in SLA and Teaching 14:111122.

Pinto, Paulo G. 2009. "Creativity and Stability in the Making of Sufi Tradition: The Tariqa Qadiriyya in Aleppo, Syria." In Sufism Today: Heritage and Tradition in the Global Community, edited by Catharina Raudvere and Leif Stenberg, 117-135. London and New York: I.B. Tauris.

Radsch, Courtney. 2009. "From Cell Phones to Coffee: Issues of Access in Egypt and Lebanon." In Surviving Field Research: Working in Violent and Difficult Situations, edited by Chandra Lekha Sriram, John C. King, Julie A. Mertus, Olga Martin-Ortega, and Johanna Herman, 91-107. New York and Abingdon. 
Rohan, Brian, and Maram Mazen. 2016. "In Egypt, Clamp on Academic Freedoms Sparks Scholar Backlash." Associated Press (February 18). http : / / bigstory . ap . org / article / c47aef5e5eb24f988779bd8e410a4d84 / egypt-clamp-academic-freedoms-sparks-scholar-backlash.

Said, Edward W. 1979. Orientalism. London: Vintage Books. ISBN: 0-394-74067-X.

Shafik, Viola. 2007. Popular Egyptian Cinema: Gender, Class, and Nation. Cairo: American University in Cairo Press.

Sholkamy, Hania. 1999. "Why Is Anthropology So Hard In Egypt?” In Between Field and Text: Emerging Voices in Egyptian Social Science, edited by Seteney Shami and Linda Herrera, 119-136. Cairo Papers in Social Science. Cairo: American University in Cairo Press.

Silverstein, Brian. 2007. "Sufism and Modernity in Turkey: From the Authenticity of Experience to the Practice of Discipline." In Bruinessen and Howell 2007, $39-60$.

Stille, Alexander. 2016. "Who Murdered Giulio Regeni?" The Guardian (October 4). https: //www . theguardian . com/world/2016/oct/04/egyptmurder-giulio-regeni.

Trentman, Emma. 2013. "Arabic and English During Study Abroad in Cairo, Egypt: Issues of Access and Use." The Modern Language fournal 97 (2): 457-473. ISSN: 1540-4781. doi: $10.1111 / \mathrm{j}$.1540-4781.2013.12013.x.

Vande Berg, M., J. Connor-Linton, and R. M. Paige. 2009. "The Georgetown Consortium Project: Interventions for Student Learning Abroad." Frontiers: The Interdisciplinary fournal of Study Abroad 18:1-75.

Weissberg, Jay. 2010. "Fires, Heat Trouble Egyptian Film Preservation.” Variety (July 31). http://variety.com/2010/biz/news/fires-heat-troubleegyptian-film-preservation-1118022406/.

Wilmsen, David. 2013. "What Is Communicative Arabic?” In Handbook for Arabic Language Teaching Professionals in the 21st Century, edited by Kassem M. Wahba, Zainab A. Taha, and Liz England, 125-138. New York and Abingdon: Routledge.

Younes, Munther. 2015. The Integrated Approach to Arabic Instruction. New York and Abingdon: Routledge. 